\title{
A Nova Lei das Estatais e a aplicação de sanções nos contratos administrativos: uma análise comparativa com a Lei Geral de Licitações*
}

The New State-Owned Enterprises
Law and the application of sanctions in government contracts: a comparative analysis with the General Bidding Law

Filipe da Silva Piovesan* José Sérgio da Silva Cristóvam***

* Artigo recebido em 21 de março de 2017 e aprovado em 7 de junho de 2017. DOI: http://dx.doi. org/10.12660/rda.v275.2017.71653

** Universidade Federal de Santa Catarina, Florianópolis, Santa Catarina, Brasil. E-mail: filipedasp@ yahoo.com.br.

Mestre em administração pela Udesc (2011). Bacharel em administração empresarial pela Esag/ Udesc (2009). Graduado em direito pelo CCJ/UFSC.

*** Universidade Federal de Santa Catarina, Florianópolis, Santa Catarina, Brasil. E-mail: jscristovam@ gmail.com.

Professor adjunto de direito administrativo no Curso de Graduação em Direito e no Programa de Mestrado do PPGD/UFSC. Doutor em direito administrativo pela UFSC (2014), com estágio de doutoramento sanduíche junto à Universidade de Lisboa - Portugal (2012). Mestre em direito constitucional pela UFSC (2005). Especialista em direito administrativo pelo Cesusc (2003). Membro fundador e presidente do Instituto Catarinense de Direito Público (ICDP). Membro fundador do Instituto de Direito Administrativo de Santa Catarina (Idasc) e da Academia Catarinense de Direito Eleitoral (Acade). Membro efetivo do Instituto dos Advogados de Santa Catarina (Iasc). Conselheiro Estadual da OAB/SC. Presidente da Comissão de Acesso à Justiça da OAB/SC. Membro da Comissão de Direito Constitucional e da Comissão da Moralidade Pública da OAB/SC. Coordenador do Grupo de Estudos em Direito Público do CCJ/UFSC (Gedip/CCJ/UFSC). 


\section{RESUMO:}

A Administração Pública apresenta um papel de destaque no cenário nacional de demanda por bens, obras e serviços, aquisições que devem ser pautadas pelo respeito a diversos princípios e regras estabelecidos, em especial a ordem constitucional e a Lei nº 8.666/1993 (Lei Geral de Licitações), que regulamenta as licitações e contratos administrativos. Entre essas disposições normativas está a prerrogativa de fiscalização da execução dos contratos administrativos, do que decorrem as atribuições dos gestores de contratos no processo de aplicação de sanções administrativas. O presente artigo tem por objetivo a análise dessas atribuições e responsabilidades, com base na Lei n⿳0 13.303/2016 (Nova Lei das Estatais), que trouxe o novo estatuto jurídico das licitações e contratos para as empresas estatais, inclusive com inovações na parte de penalidades administrativas. No estudo das mudanças (materiais e processuais) trazidas pela Nova Lei das Estatais, no âmbito das sanções administrativas, pretende-se uma análise comparativa com a Lei Geral de Licitações. O método de abordagem será o dedutivo, pelo método de procedimento histórico e comparativo e pela técnica de pesquisa bibliográfica e documental, com análise da legislação envolvida, da doutrina sobre o tema e de outros documentos que se mostraram importantes ao desenvolvimento do trabalho.

\section{PALAVRAS-CHAVE:}

Contratos administrativos - gestão de contratos administrativos processo de aplicação de sanções administrativas - Nova Lei das Estatais - Lei Geral de Licitações

\section{ABSTRACT:}

The public administration presents a prominent role in the national scenario of demand for products, works and services, acquisitions that must be guided by respect for several established principles and rules, especially the constitutional order and Law number 8.666/1993 (General Bidding Law), which regulates bids and administrative contracts. Among these normative provisions is the prerogative to supervise the execution of administrative contracts, resulting in the attributions of contract managers in the process of applying administrative sanctions. The purpose of this article is to analyze these attributions and responsibilities, based on Law 13.303/2016 (State-Owned Enterprises Law), which brought the new 
legal statute of bids and contracts for state-owned enterprises, including innovations in administrative penalties. In the study of the changes (material and procedural) brought by the State-Owned Enterprises Law, in the scope of administrative sanctions, a comparative analysis is intended with the General Bidding Law. The method of approach will be the deductive, by the method of historical and comparative procedure and by the technique of bibliographical and documentary research, with analysis of the legislation involved, the doctrine about the subject and other documents that have proved important to the development of the work.

\section{KEYWORDS:}

Government contracts - management of administrative contracts application process of administrative sanctions - New State-Owned Enterprises Law - General Bidding Law

\section{Introdução}

A Administração Pública ${ }^{1}$ brasileira ostenta relevante papel na economia nacional como consumidora de bens, obras e serviços, e as compras públicas em geral representam uma considerável fatia do Produto Interno Bruto (PIB). E a satisfação dessas necessidades precisa ser promovida sob o pálio dos princípios constitucionais gerais da Administração Pública direta e indireta, associado ao respeito às prescrições constitucionais e infraconstitucionais específicas, entre as quais o art. 37, inciso XXI, da Constituição Federal, e a Lei no 8.666, de 21 de junho de 1993 (Lei Geral de Licitações), instituidora das normas reitoras das licitações e contratos para toda a Administração Pública direta e indireta.

Sobre esse tema, desde o advento da Lei $\mathrm{n}^{\mathrm{o}}$ 13.303, de 30 de junho de 2016 (Nova Lei das Estatais), restou satisfeita a vontade constitucional insculpida no art. 173, $\S 1^{\circ}$, da Constituição Federal, com a regulamentação do

\footnotetext{
A fim de evitar quaisquer confusões, cumpre indicar que eventual uso da expressão escrita com letras minúsculas se refere à atividade administrativa, restando a grafia com maiúsculas - Administração Pública - quando alusiva ao conjunto de entidades jurídicas que podem desenvolver a atividade administrativa de interesse coletivo. No sentido do acordo semântico aqui proposto, consultar: CAETANO, Marcello. Manual de direito administrativo. Coimbra: Livraria Almedina, 1991. v. I.
} 
estatuto jurídico da empresa pública, da sociedade de economia mista e de suas subsidiárias, no âmbito da União, dos estados, do Distrito Federal e dos municípios. Diante dessa nova legislação, aqueles entes integrantes da Administração Pública indireta passam a dispor de um marco legal próprio sobre licitações e contratos a lhes impor um novo cenário. ${ }^{2}$

Inclusive, na parte da gestão dos contratos administrativos, aqui entendida como o acompanhamento e a fiscalização do cumprimento de todas as obrigações contratuais assumidas pelas partes, bem como o emprego de esforços para a perfeita consecução dos objetivos pretendidos com a celebração do contrato, surgiram inovações decorrentes da Nova Lei das Estatais, a merecer reflexões teóricas e implicar mudanças práticas na consecução da respectiva atividade administrativa.

Entre as funções abrangidas pelo gestor de contratos, uma das mais sensíveis repousa na prerrogativa de penalização dos contratados, ou seja, na possibilidade de aplicação de sanções administrativas. Por representar uma atribuição de relevo e que gera inegável impacto na atividade administrativa, o estudo pretende analisar as inovações materiais e, principalmente, processuais trazidas pela Nova Lei das Estatais em comparação com a Lei Geral de Licitações, em especial no âmbito das sanções administrativas.

A análise partirá de uma breve recuperação sobre alguns pontos destacados do regime de contratação administrativa e sua respectiva gestão, avançando para a apresentação das sanções administrativas e a exposição sobre as inovações trazidas pela Nova Lei das Estatais, com o estudo comparativo com o disposto na Lei Geral de Licitações. As considerações sobre as principais modificações têm maior ênfase nos aspectos concernentes ao processo de aplicação das sanções administrativas.

Por fim, cumpre ressaltar que a justificativa do estudo repousa exatamente na relevância de algumas das inovações trazidas pena Nova Lei das Estatais, que ainda têm pouco tempo de vigência, com prazo de 24 meses para a adequação/adaptação das atuais empresas estatais, existentes ao tempo da sua entrada em vigor (art. 91), um estudo que apenas dá seus primeiros passos. Daí a necessidade e pertinência de estudos e análises comparativas, com vistas à melhor aplicação dessa nova legislação.

2 Para uma análise panorâmica sobre as principais mudanças trazidas pela Nova Lei das Estatais, consultar: JUSTEN FILHO, Marçal (Org.). Estatuto jurídico das empresas estatais: Lei 13.303/16 “Lei das Estatais". São Paulo: Revista dos Tribunais, 2016; NOHARA, Irene Patrícia. Mudanças promovidas pela nova Lei das Estatais: pontos fortes e fracos. Disponível em: <www.direitoadm.com.br $>$. Acesso em: 4 jun. 2017. 


\section{Sobre o regime dos contratos administrativos}

Ultrapassado o cumprimento de uma série de etapas, nas fases interna e externa do certame licitatório, têm lugar a homologação da licitação e a convocação do vencedor pela entidade promotora, para firmar contrato com a Administração - a chamada adjudicação. ${ }^{3}$

A Lei nº 8.666/93 estabelece, nos artigos do Capítulo III (Dos Contratos), Seção II (Da Formalização dos Contratos), a obrigatoriedade da formalização da contratação por meio de instrumento de contrato, ressalvadas aquelas que não ultrapassem $5 \%$ do limite estabelecido no art. 23, inciso II, alínea "a", ou seja, $\mathrm{R} \$ 4.000,00$, que podem ser contratados verbalmente pela Administração.

Segundo ensina José dos Santos Carvalho Filho, ${ }^{4}$ o contrato administrativo pode ser de diferentes espécies, quais sejam:

- Contrato de Obra: relativo a construção, reforma, fabricação, recuperação ou ampliação de determinado bem público;

- Contrato de Serviços: contempla a prestação de serviços destinados à obtenção de determinada utilidade concreta de interesse da Administração e/ou dos cidadãos;

- Contrato de Fornecimento (ou Compras): abrange as aquisições de bens móveis necessários à consecução dos serviços administrativos e;

- Contrato de Concessão e de Permissão: delegação de execução remunerada de serviço ou obra, além da exploração de bem público.

Com efeito, independentemente da espécie do contrato, o art. 55 da Lei Geral de Licitações prescreve que são cláusulas necessárias em todo contrato as que estabeleçam: a definição do objeto; o regime de execução ou forma de fornecimento; o preço e as condições de pagamento; o crédito pelo qual correrá a despesa; as garantias para assegurar a execução; os direitos e deveres das partes; o reconhecimento dos direitos da Administração; a vinculação ao edital; entre outras.

Alinhados esses breves apontamentos, faz-se forçoso traçar considerações sobre a definição de contrato administrativo. $\mathrm{O}$ art. $2^{\circ}$, parágrafo único, da Lei Geral de Licitações define contrato administrativo como “[...] todo e qualquer ajuste entre órgãos ou entidades da Administração Pública e particulares, em

MELLO, Celso Antônio Bandeira de. Curso de direito administrativo. 32. ed. São Paulo: Malheiros, 2015.

4 CARVAlHO FILHO, José dos Santos. Manual de direito administrativo. 31. ed. São Paulo: Atlas, 2017. 
que haja um acordo de vontades para a formação de vínculo e a estipulação de obrigações recíprocas, seja qual for a denominação utilizada".

A conceituação do contrato administrativo, direcionada pela definição legal, reforça avidamente a participação da Administração Pública e a imposição da prossecução do interesse público ${ }^{5}$ como traço característico desse modelo de contrato. Para Maria Sylvia Zanella Di Pietro ${ }^{6}$ e Celso Antônio Bandeira de Mello, ${ }^{7}$ o contrato administrativo pode ser entendido como um tipo de avença travada entre Administração Pública e terceiros, no qual as cláusulas pactuadas estão sujeitas às imposições de interesse público, segundo o regime jurídico de direito público. Complementando, Hely Lopes Meirelles lembra que o contrato administrativo, em regra, é consensual, formal, oneroso, cumulativo e realizado intuitu personae (deve ser executado pelo próprio contratado) ${ }^{8}$

Nesse quadrante, emerge também o debate em torno das chamadas cláusulas exorbitantes, comumente definidas como cláusulas que excedem do direito comum para consignar uma posição de vantagem e proeminência do poder público, como se pode ver do disposto no art. 58 da Lei Geral de Licitações. ${ }^{9}$

Segundo tais prerrogativas, e nos limites legais, a Administração Pública possui a prerrogativa de, unilateralmente, impor ao contratado: alterações de determinados aspectos do instrumento contratual; extinção contratual; realização de gerenciamento e fiscalização; aplicação de sanções quando

5 Ultrapassam os limites desse estudo a análise e o instigante debate em torno do conceito de interesse público e sua centralidade para o direito administrativo contemporâneo, em especial no que toca à discussão em torno do chamado princípio da supremacia do interesse público e a crítica que lhe é endereçada. Para o estudo sobre essa temática, bem como a construção do regime jurídicoadministrativo comum ao paradigma da Administração Pública democrática, a partir dos princípios constitucionais estruturantes da dignidade da pessoa humana, do estado democrático de direito e do princípio republicano, consultar: CRISTÓVAM, José Sérgio da Silva. Administração pública democrática e supremacia do interesse público: novo regime jurídico-administrativo e seus princípios constitucionais estruturantes. Curitiba: Juruá, 2015.

6 DI PIETRO, Maria Sylvia Zanella. Direito administrativo. 30. ed. Rio de Janeiro: Forense, 2017.

7 Celso Antônio Bandeira de Mello, Curso de direito administrativo, op. cit.

8 MEIRELLES, Hely Lopes. Direito administrativo brasileiro. 13. ed. São Paulo: Revista dos Tribunais, 1987.

9 Para uma análise aprofundada da temática das cláusulas exorbitantes, desde a controvertida recuperação histórica das distinções adjetiva (processual) e substantiva (natureza jurídica) entre contratos privados e contratos administrativos até a atual polêmica sobre a eficiência da gestão privada de serviços públicos, e uma tipologia em três diferentes classes (cláusulas de executoriedade; cláusulas de jus variandi; e cláusulas de previsão de efeitos sobre terceiros), consultar: MOREIRA NETO, Diogo de Figueiredo. O futuro das cláusulas exorbitantes nos contratos administrativos. In: ARAGÃO, Alexandre dos Santos; MARQUES NETO, Floriano de Azevedo (Coord.). Direito administrativo e seus novos paradigmas. Belo Horizonte: Fórum, 2008. 
ocorrer desvios na execução contratual. Por oportuno, cumpre ressaltar que, independentemente da inovação unilateral realizada pela Administração Pública, fica assegurada a equação econômico-financeira originalmente pactuada. ${ }^{10}$

\section{Sobre a gestão dos contratos administrativos}

Em geral, há uma ideia de que, no regime de contratação pública, existiria uma espécie de direcionamento maciço do foco ao procedimento licitatório, restando para a fase de execução contratual e, por conseguinte, à gestão de contratos pouco ou nenhum interesse. ${ }^{11}$

Nada obstante, a execução contratual também deveria reclamar larga atenção e interesse do poder público e dos sistemas de controle, vez que nela podem ocorrer graves e danosas implicações/distorções. Inclusive, os Tribunais de Contas da União e dos estados têm efetivado sua competência na análise sobre a fiscalização do acompanhamento dos contratos pela Administração, no intuito de coibir irregularidades e responsabilizar os executores e/ou gestores de contratos, nos limites das suas infrações. Parece crescente certa tendência mais "punitivista", por vezes até extremada, com a aplicação de sanções administrativas quando demonstradas situações de atuação irregular por parte do representante da Administração. ${ }^{12}$

A legislação existente acerca do agente público responsável pelo acompanhamento dos contratos administrativos é genérica, o que dificulta a delimitação da função e, por consequência, uma orientação mais precisa das atribuições que contém. Nesse sentido:

10 JUSTEN FILHO, Marçal. Curso de direito administrativo. 12. ed. São Paulo: Revista dos Tribunais, 2016.

11 VIEIRA, Antonieta Pereira et al. Gestão de contratos de terceirização na administração pública. 3. ed. Belo Horizonte: Fórum, 2008.

12 FERNANDES, Jorge Ulisses Jacoby. Tribunais de Contas do Brasil: jurisdição e competência. 2. ed. Belo Horizonte: Fórum, 2008. 
Tabela 1

\section{Legislação existente sobre gestão de contratos}

\begin{tabular}{|l|c|}
\hline \multicolumn{1}{|c|}{ Legislação } & O que diz sobre gestão de contratos \\
\hline Lei no $8.666 / 93$ - Art. 67 & $\begin{array}{c}\text { Designação de um representante para } \\
\text { acompanhar e fiscalizar a execução do } \\
\text { contrato. De acordo com a providência ou } \\
\text { decisão a ser tomada, este representante } \\
\text { deverá repassar a situação aos seus } \\
\text { superiores. }\end{array}$ \\
\hline Decreto $\mathrm{n}^{\mathrm{o}} 2.271 / 97$ - Art. 6 & $\begin{array}{c}\text { Designação de um gestor do contrato. } \\
\text { responsável pelo fiel cumprimento do } \\
\text { pactuado. }\end{array}$ \\
\hline Decreto $\mathrm{n}^{0} 5.450 / 05$ - Art. 9 & $\begin{array}{c}\text { No termo de referência deverão constar } \\
\text { os procedimentos de fiscalização e } \\
\text { gerenciamento do contrato. }\end{array}$ \\
\hline
\end{tabular}

Fonte: Elaboração própria.

A falta de legislação mais específica sobre o tema torna confusa a terminologia da função e suas atribuições. No tocante à terminologia a ser aplicada ao acompanhante do contrato, tem-se uma situação de imprecisão. Encontram-se na Administração Pública as seguintes nomenclaturas: fiscal, gestor, fiscalizador, executor, órgão de fiscalização, entre outras. Com relação às atribuições, a situação é ainda menos alentadora. Por vezes, a função relativa à fiscalização e aquela concernente à gestão de contratos se sobrepõem na atividade das organizações públicas. Há casos em que ambas as funções são realizadas por um mesmo agente público, o que dificulta o correto acompanhamento contratual.

Apesar dessa sobreposição, algumas instituições diferenciam as funções a partir da seguinte consideração: 1. A fiscalização abarca o acompanhamento físico do contrato, em seu cotidiano; 2 . A gestão é aquela realizada pela área de contratos, com servidores qualificados e que respondem pelo acompanhamento do enquadramento legal dos contratos, o estudo das alterações necessárias, as repactuações, os documentos necessários, entre outros. O fiscal, conhecedor técnico do objeto, representando a área demandante; o gestor do contrato, sabedor das questões legais, representando a área de contratos. ${ }^{13}$

13 Antonieta Pereira Vieira et al., Gestão de contratos de terceirização na administração pública, op. cit. 
Com a apresentação do contexto em que está inserida a função da gestão de contratos, parte-se para sua conceituação. Essa gestão, em sentido amplo, consiste no acompanhamento e na execução contratual por parte do gestor do contrato, o qual, por conseguinte, precisa ser proativo e agir de maneira preventiva para que os resultados esperados sejam alcançados. ${ }^{14}$

Minudenciando a gestão de contratos, pode-se dizer que ela consiste em uma atividade de controle contínuo do objeto contratado, "[...] com a finalidade de examinar e verificar se sua execução obedece às especificações, ao projeto, aos prazos estabelecidos e demais obrigações previstas no contrato" ${ }^{15}$

A importância desta função pode ser vislumbrada em sua própria definição, que essencialmente visa garantir que as necessidades das partes, expostas no instrumento contratual, sejam fielmente atingidas. Além deste aspecto, Walter Freitas ressalta que a importância da gestão contratual repousa no fato de que um contrato possui capital e risco envolvido. Nenhum agente, seja ele público ou privado, quer ou mesmo pode incorrer em riscos desnecessários e consequente perda de capital. Nesse sentido, não somente a área de contratos deve ser responsável pela sua condução; toda a organização deve ter ciência sobre sua participação nesse processo. ${ }^{16}$

Nessa mesma toada, Antônio Carlos Cintra do Amaral lembra que o processo de contratação é longo e que a gestão de contratos, assim como a licitação e o planejamento, é apenas etapa daquele. Com frequência, discorre o autor, quem planeja não sabe da execução dos contratos e quem os administra desconhece o planejamento da contratação. Se houvesse uma visão sistêmica do processo, o fluxo de informações entre as partes integrantes da Administração seria muito maior. Os problemas e os acertos seriam evidenciados. ${ }^{17}$

Ainda sobre a importância da amplitude que a função de gestão de contratos deve assumir, Cleusa Pimentel expõe que, para aquela ser desempenhada com eficiência pelo respectivo gestor, deve ser iniciada antes mesmo da formalização da contratação. Nesse sentido, o marco inicial da gestão deve ocorrer já na etapa de planejamento da contratação, onde as alternativas

14 SUPERIOR TRIBUNAL DE JUSTIÇA. Manual do gestor de contratos. 2005. Disponível em: <http:// bdjur.stj.gov.br/dspace/handle/2011/2175>. Acesso em: 14 out. 2016.

15 ROCHA, Wagner. Gestão pública - Módulo V - 14. Gestão de contratos administrativos. 2013. Disponível em: <http://gestaopublicaeficiente.blogspot.com.br/2013/06/gestao-publica-modulo-v14-gestao-de.html>. Acesso em: 14 out. 2016.

16 FREITAS, Walter. Gestão de contratos: melhores práticas voltadas aos contratos empresariais. São Paulo: Atlas, 2009.

17 AMARAL, Antônio Carlos Cintra do. Licitação e contrato administrativo: estudos, pareceres e comentários. 2. ed. Belo Horizonte: Fórum, 2009. 
de suprimentos da Administração ainda estão sendo confeccionadas. Além de auxiliar no planejamento, a gestão de contratos deve ter continuidade na etapa licitatória. Destarte, acompanhando integralmente o processo, o gestor, além de auxiliar, também traz para si todas as condições de executar o gerenciamento do contrato com a máxima eficiência e eficácia. ${ }^{18}$

Para o exercício dessa função, as organizações públicas têm desenvolvido manuais que buscam delinear o perfil e as atribuições de um gestor de contratos administrativos.

Tabela 2

Perfil e atribuições de um gestor de contratos administrativos

\begin{tabular}{|c|c|}
\hline Perfil & Atribuições \\
\hline \multirow[t]{2}{*}{ a. gozar de boa reputação ético-profissional; } & $\begin{array}{l}\text { 1. Acompanhar o desenvolvimento do Projeto } \\
\text { Básico e da licitação; }\end{array}$ \\
\hline & 2. Abrir pasta para cada contrato sob sua gestão; \\
\hline \multirow[t]{2}{*}{$\begin{array}{l}\text { b. conhecer com profundidade o objeto a ser } \\
\text { gerenciado; }\end{array}$} & $\begin{array}{l}\text { 3. Promover a comunicação entre áreas internas } \\
\text { e os fornecedores; }\end{array}$ \\
\hline & $\begin{array}{l}\text { 4. Aconpanhar e atestar cumprimento dos } \\
\text { eventos contratuais, enviando a devida } \\
\text { comprovação à contratada e demais áreas } \\
\text { interessadas; }\end{array}$ \\
\hline \multirow{2}{*}{$\begin{array}{l}\text { c. não estar, preferencialmente, respondendo } \\
\text { a processo de sindicância ou processo } \\
\text { administrativo disciplinar; }\end{array}$} & 5. Gerenciar os prazos de vigência e execução; \\
\hline & $\begin{array}{l}\text { 6. Proceder com as necessárias aditivações } \\
\text { contratuais, bem como com as possíveis } \\
\text { rescisões; }\end{array}$ \\
\hline \multirow{2}{*}{$\begin{array}{l}\text { d. não possuir em seus registros funcionais } \\
\text { punições em decorrência de atos lesivos ao } \\
\text { patrimônio publico; }\end{array}$} & $\begin{array}{l}\text { 7. Receber, analisar e encaminhar ao } \\
\text { Departamento Financeiro as Notas Fiscais; }\end{array}$ \\
\hline & 8. Registrar todas as ocorrências contratuais; \\
\hline \multirow{2}{*}{$\begin{array}{l}\text { e. não haver sido responsabilizado por } \\
\text { irregularidades junto ao Tribunal de Contas da } \\
\text { União ou junto a Tribunais de Contas de Estado, } \\
\text { do Distrito Federal ou de Município; }\end{array}$} & $\begin{array}{l}\text { 9. Proceder com a aplicação das sanções } \\
\text { administrativas, nos casos de descumprimento } \\
\text { do contrato; }\end{array}$ \\
\hline & $\begin{array}{l}\text { 10. Informar à área responsável a avaliação } \\
\text { do fornecedor, conforme mensuração do seu } \\
\text { desempenho; }\end{array}$ \\
\hline $\begin{array}{l}\text { f. não haver sido condenado em processo } \\
\text { criminal por crimes contra a Administração } \\
\text { Pública, capitulados no Título XI, Capítulo I, do } \\
\text { Código Penal Brasileiro, na Lei 7.492/1986 e na } \\
\text { Lei 8.429/1992. }\end{array}$ & $\begin{array}{l}\text { 11. Organizar cronologicamente, numerar, } \\
\text { rubricar e arquivar as pastas dos contratos } \\
\text { encerrados. }\end{array}$ \\
\hline
\end{tabular}

Fonte: Elaborada com base em materiais do Superior Tribunal de Justiça, do Tribunal de Contas do Estado de Tocantins e da Universidade Federal de Viçosa. ${ }^{19}$

18 PIMENTEL, Cleusa. Roteiro do gestor de contratos públicos. São Paulo: Vianna Treinamento e Assessoria, 2010. CD-ROM.

19 Nesse sentido, consultar: SUPERIOR TRIBUNAL DE JUSTIÇA. Manual do gestor de contratos. 2005. Disponível em: <http://bdjur.stj.gov.br/dspace/handle/2011/2175>. Acesso em: 14 out. 2016; 
Da análise da referida tabela, vê-se que, em termos de perfil, grande atenção é despendida acerca da idoneidade do gestor. No tocante às suas atribuições, é possível verificar o apontado anteriormente sobre a necessidade de possuir a visão sistêmica do processo de contratação. Ademais, a presença da informação e da troca de informações é visualizada em algumas atribuições. Com relação a essa última afirmação, Walter Freitas ressalta a importância do monitoramento dos eventos contratuais críticos, identificando formas para armazenagem e acesso à informação, no que convencionou chamar de quarta fase do ciclo de vida do contrato. ${ }^{20}$

Para Antônio Carlos Cintra do Amaral essa troca de informações varia de acordo com o público. No que tange à articulação interna (troca de informações dentro da organização), deve-se pautar pela informalidade, decorrente de confiança mútua entre as partes envolvidas. No tocante à articulação externa, em regra, privilegia-se a formalidade dos documentos escritos. ${ }^{21}$

A partir desse amplo arcabouço de atribuições, embora se identifiquem iniciativas de normatização da função de gestor de contratos, Antonieta Pereira Vieira dedicou-se a discorrer sobre uma possível minuta de norma de gestão de contratos. Nessa minuta reservou espaço para o embasamento legal da função, denominações e procedimentos, atribuições do gestor e necessidade de revisão da norma. ${ }^{22}$

De modo geral, a referida redação guarda semelhanças com o constante dos supramencionados manuais das organizações públicas. No entanto, ressalvaram-se as distorções na execução contratual, seja no tratamento dado a elas, a necessidade de comunicação aos superiores, a identificação de falhas para aperfeiçoamento dos fornecedores, entre outras. Para a consecução dessa situação, Walter Freitas propõe que sejam criados indicadores sobre a gestão de contratos; dessa forma, poder-se-ia realizar um monitoramento contínuo dos gargalos e dos eventos mais corriqueiros, com a realização dos devidos reparos. ${ }^{23}$

TRIBUNAL DE CONTAS DO ESTADO DO TOCANTINS. Manual de gestão de contratos. 2007. Disponível em: <www.tce.to.gov.br/sitephp/aplic/controleInterno/docs/Manual_Gestao_Contrato. pdf >. Acesso em: 14 out. 2016; UNIVERSIDADE FEDERAL DE VIÇOSA. Manual de gestão de contratos. 2008. Disponível em: <ftp://ftp.ufv.br/Proplan2/Formularios/manualGestaoContratos.pdf>. Acesso em: 14 out. 2016.

20 Walter Freitas, Gestão de contratos, op. cit.

21 Antônio Carlos Cintra do Amaral, Licitação e contrato administrativo, op. cit.

22 Antonieta Pereira Vieira et al., Gestão de contratos de terceirização na administração pública, op. cit.

23 Além de indicadores, Walter Freitas apresenta algumas propostas, as quais ele denomina de melhores práticas, com vistas à prática da gestão contratual eficiente e eficaz, como: 1. Criação de uma metodologia de gestão de contratos; 2 . Utilização de um sistema informatizado de gestão de 


\section{Sobre as sanções administrativas previstas na legislação anterior à Lei das Estatais}

A Lei Geral de Licitações rege, em seu capítulo IV, as sanções administrativas, compreendidas entre os arts. 86 e 88. Nesses dispositivos constam quatro tipos, quais sejam: a) advertência; b) multa; c) suspensão temporária de participação em licitação e impedimento de contratar com a Administração; d) declaração de inidoneidade para licitar ou contratar com a Administração Pública.

Na mesma linha, a Lei $\mathrm{n}^{-}$10.520/2002, que instituiu a modalidade de licitação denominada pregão, prescreve em seu art. $7^{\circ}$ a sanção administrativa de impedimento de licitar e contratar por um período de até cinco anos. Tal penalidade é aplicável, entre outras situações, aos casos em que a contratada retarda a execução de seu objeto.

Retornando às prescrições da Lei Geral de Licitações, o inciso I do art. 87 dispõe sobre a advertência, que consiste em uma comunicação com teor de censura leve, realizada pela Administração, em face de um comportamento do contratado, visando que ele se atente e evite uma lesão definitiva e irreversível ao interesse público. ${ }^{24}$ Trata-se da mais branda das sanções, tendo em vista que não impõe efeitos financeiros e as consequências morais são mínimas, quando comparadas com as existentes nas demais sanções. ${ }^{25}$

A multa é também conhecida como cláusula penal ou pena convencional. Representa uma espécie de pré-ajuste a respeito do quanto é devido, a título de perdas e danos, no caso de comportamento faltoso por parte do contratado, o que confere segurança e previsibilidade ao processo. ${ }^{26}$ Trata-se de verdadeira punição pecuniária, ao impor redução do patrimônio do contratado em favor da Administração. Por essa razão, sua aplicação está condicionada a previsão editalícia e contratual. ${ }^{27}$

Com efeito, a Lei Geral de Licitações prevê duas espécies de multas. A contida no caput do art. 86 contempla o sancionamento em caso de atraso no

contratos; e 3. Desenvolvimento e manutenção de uma central de conhecimento de gerenciamento de contratos. Walter Freitas, Gestão de contratos, op. cit.

24 NIEBUHR, Joel de Menezes. Licitação pública e contrato administrativo. 4. ed. Belo Horizonte: Fórum, 2015.

25 JUSTEN FILHO, Marçal. Comentários à lei de licitações e contratos administrativos. 9. ed. São Paulo: Dialética, 2002.

26 Joel de Menezes Niebuhr, Licitação pública e contrato administrativo, op. cit.

27 PÉRCIO, Gabriela Verona. Contratos administrativos. Curitiba: Negócios Públicos do Brasil, 2008. 
cumprimento de uma obrigação contratual, conhecida como multa moratória. A segunda, disposta no inciso II do art. 87, refere-se ao descumprimento parcial ou total de obrigações contratuais, sendo conhecida como multa compensatória. Em síntese, enquanto a primeira trata do cumprimento tardio, a segunda trata do não cumprimento, seja ele parcial ou total, de um compromisso assumido pelo contratado. ${ }^{28}$

As sanções previstas nos incisos III e IV do art. 87, respectivamente, a suspensão temporária de participação em licitação e o impedimento de contratar com a Administração e a declaração de inidoneidade para licitar ou contratar com a Administração Pública, são consideradas extremamente penosas e pressupõem a prática de condutas igualmente graves. ${ }^{29}$

A suspensão temporária de licitar e contratar com a Administração é aplicável naqueles casos em que o descumprimento, parcial ou total, do contrato decorre de práticas consideradas graves. $\mathrm{O}$ dispositivo determina seu prazo máximo em dois anos e a definição de prazo inferior pode ser feita pelo ente público, a partir de critérios de gradação da intensidade da falta cometida pelo contratado. Por sua vez, a declaração de inidoneidade para licitar e contratar com a Administração Pública é aplicável naqueles casos ainda mais graves de descumprimento, durando o tempo em que os motivos que a ensejarem continuarem a existir. Inclusive, a competência para sua imposição restringe-se a ministro de Estado, secretário estadual ou municipal. ${ }^{30}$

Joel de Menezes Niebuhr defende que o legislador foi infeliz ao definir essas duas últimas sanções, pois a redação é obscura ao distinguir a natureza de cada uma delas e seus respectivos efeitos, gerando confusão na aplicação prática. ${ }^{31}$ Já Gabriela Verona Pércio destaca que a abrangência de ambas foi equivocadamente definida, porquanto diferentes - Administração para uma e Administração Pública para outra - , fazendo emergir dúvidas quanto à extensão a ser considerada. ${ }^{32}$

Há, ainda, na doutrina especializada corrente que considera a previsão de rescisão unilateral do contrato uma quinta modalidade de sanção administrativa. ${ }^{33}$

\footnotetext{
Joel de Menezes Niebuhr, Licitação pública e contrato administrativo, op. cit.

Marçal Justen Filho, Comentários à lei de licitações e contratos administrativos, op. cit.

Gabriela Verona Pércio, Contratos administrativos, op. cit.

Joel de Menezes Niebuhr, Licitação pública e contrato administrativo, op. cit.

Gabriela Verona Pércio, Contratos administrativos, op. cit.

Joel de Menezes Niebuhr, Licitação pública e contrato administrativo, op. cit.
} 
Cumpre ressaltar, ainda, a existência de corrente a defender que "[...] as penalidades administrativas apresentam configuração similar às de natureza penal, sujeitando-se a regime jurídico senão idêntico ao menos semelhante" ${ }^{34}$ Disso decorre que a efetivação de sanções administrativas está situada no campo do direito administrativo sancionatório ${ }^{35}$ e sujeita à observância de uma série de direitos e garantias dos contratados em geral, a partir da cogente imposição de alguns princípios, como legalidade em sentido estrito, devido processo legal, contraditório, ampla defesa etc. ${ }^{36}$

Com efeito, a "lei é o instrumento apto a criar sanções administrativas e estabelecer as respectivas hipóteses de incidência". ${ }^{37}$ Por conseguinte, a partir da positivação de uma conduta e sua respectiva penalidade, é dever da Administração aplicá-la quando e somente quando a situação fática der respaldo, ou seja, representa verdadeira atividade vinculada da Administração. ${ }^{38}$ Corroborando esse entendimento, Gabriela Verona Pércio complementa que não há margem para discricionariedade por parte do agente público, "[...], ou seja, descabendo qualquer ponderação sobre conveniência e oportunidade do sancionamento". ${ }^{39}$

Cabe ressaltar, ainda, que a sanção administrativa e sua respectiva aplicação se sujeitam aos princípios da especificação, tipicidade, razoabilidade, proporcionalidade $^{40}$ (compatibilidade entre gravidade da conduta e da sanção) e culpabilidade (pressupõe a existência mínima de culpa - negligência, imprudência ou imperícia). No âmbito processual, prevalece o entendimento de que o processo administrativo sancionatório deve buscar revelar a verdade dos fatos antes de se chegar à conclusão penalizadora. ${ }^{41}$

A Lei Geral de Licitações não traz de maneira sistematizada as regras atinentes ao processo administrativo sancionador. Normas esparsas e insuficientes dão um contorno de algumas fases que a Administração deva

34 Marçal Justen Filho, Comentários à lei de licitações e contratos administrativos, op. cit., p. 567.

35 Para um estudo panorâmico sobre o direito administrativo sancionatório, consultar: OSÓRIO, Fábio Medina. Direito administrativo sancionador. 2. ed. São Paulo: Revista dos Tribunais, 2005.

36 Sobre a relevante e rica temática das sanções administrativas aplicáveis aos licitantes e contratados, consultar: DIAS, Eduardo Rocha. Sanções administrativas aplicáveis a licitantes e contratados. São Paulo: Dialética, 1997.

37 Gabriela Verona Pércio, Contratos administrativos, op. cit., p. 96.

38 OLIVEIRA, Yara Beatriz Cruz de. Dosimetria da penalização nos contratos administrativos: dinâmica para a formulação do juízo de proporcionalidade. Porto Alegre: Ingep, 2013.

39 Gabriela Verona Pércio, Contratos administrativos, op. cit., p. 95.

40 Para um estudo panorâmico sobre a teoria dos princípios e, em especial, as máximas da razoabilidade e proporcionalidade, consultar: CRISTÓVAM, José Sérgio da Silva. Princípios constitucionais: razoabilidade, proporcionalidade e argumentação jurídica. 2. ed. Curitiba: Juruá, 2016.

41 Marçal Justen Filho, Comentários à lei de licitações e contratos administrativos, op. cit. 
respeitar. $\mathrm{O} \S 2^{\circ}$ do art. 87 prevê que ao contratado seja dado apresentar defesa prévia em até cinco dias úteis depois de instaurado o processo. Já a alínea " $\mathrm{f}$ " do inciso I do art. 109 traz o cabimento de recurso, no prazo de cinco dias úteis a contar da intimação, nos casos de aplicação de advertência, suspensão temporária e multa. Inclusive, cumpre ressaltar que, da leitura do $\S 20$ do art. 109, retira-se que não há previsão de efeito suspensivo para recursos apresentados diante da aplicação daquelas penalidades. ${ }^{42}$

Sobre o tema, cabe considerar a viva possibilidade de aplicação supletiva da Lei $\mathrm{n}^{\mathrm{o}}$ 9.784, de 29 de janeiro de 1999, que regulamenta o processo administrativo no âmbito da Administração Pública federal, mas que também ostenta aplicabilidade no âmbito dos estados, Distrito Federal e municípios, desde que ausente legislação específica desses entes federados, pelo que não se mostra minimamente subsistente a ideia de aplicação de sanções administrativas sem o devido processo legal, o contraditório e a ampla defesa, garantias que decorrem da ordem constitucional estabelecida e que devem ser a todos vivamente asseguradas.

Cumpre, doravante, analisar o cenário das licitações e contratos administrativos realizados pelas empresas públicas e sociedades de economia mista, com o advento da Lei das Estatais, ${ }^{43}$ em especial as inovações trazidas para seu regime administrativo sancionador.

\section{As sanções administrativas com o advento da Lei das Estatais}

A Nova Lei das Estatais representa o marco de um novo regime normativo para as empresas públicas e sociedades de economia mista. A partir da promulgação daquela legislação, esses entes da Administração Pública passam a contar com um regulamento próprio, inclusive em matéria de licitações e contratos. Joel de Menezes Niebuhr ressalta que essa ideia não é nova, vez que prevista no inciso II do $\$ 1^{\circ}$ do art. 173 da Constituição Federal, norma incluída pela Emenda Constitucional no $19 / 1998$. $^{44}$

42 Joel de Menezes Niebuhr, Licitação pública e contrato administrativo, op. cit.

43 Para uma análise panorâmica sobre o novo regime licitatório e contratual trazido pela Nova Lei das Estatais, consultar: GUIMARÃES, Edgar; SANTOS, José Anacleto Abduch. Lei das estatais: comentários ao regime jurídico licitatório e contratual da Lei 13.303-16. Belo Horizonte: Fórum, 2017.

44 NIEBUHR, Joel de Menezes. Aspectos destacados do novo regime de licitações e contratações das estatais. 2016. Disponível em: <www.mnadvocacia.com.br/publicacoes/novo-regime-de-licitacoes-econtratacoes-das-estatais/>. Acesso em: 10 nov. 2016. 
Sobre essa nova legislação, um primeiro aspecto polêmico repousa no momento em que a lei entra em vigor e sua aplicação para as estatais existentes quando do seu advento. $\mathrm{O}$ art. 97 diz que a lei entra em vigor a partir da data de sua publicação. Já o caput do art. 91 diz que as empresas públicas e as sociedades de economia mista já constituídas antes da vigência da lei terão 24 meses para realizar as adaptações necessárias. Especificadamente sobre a matéria de licitações e contratos, o $§ 3^{\circ}$ do mesmo art. 91 define que continuarão regidos pela legislação anterior todos os processos licitatórios e as contratações iniciados ou celebrados até o fim dos referidos 24 meses.

Com razão, Joel de Menezes Niebuhr considera o prazo demasiado longo para que se possa verificar na prática se o novo diploma legal irá funcionar como imaginado, salvo se for criada alguma nova empresa pública ou sociedade de economia mista, o que parece pouco provável, ante o contexto político e econômico atual. ${ }^{45}$

Independentemente da polêmica sobre a efetiva aplicabilidade da lei, como toda novidade, seu advento traz preocupações. Isso porque, embora venha com a promessa de simplificar o processo de contratação e torná-lo mais atraente aos interessados da iniciativa privada e, por conseguinte, tornar estas empresas estatais mais competitivas no mercado, as inovações são inegavelmente sensíveis. Na sequência, uma tabela comparativa apresenta as modificações mais expressivas, com ênfase para aquelas que podem trazer impacto ao regime das sanções administrativas.

45 Ibid. 
Tabela 3

\section{Síntese comparativa entre a Lei Geral de Licitações e a Nova Lei das Estatais}

\begin{tabular}{|c|c|}
\hline Lei $n^{0}$ 8.666/1993 & Lei $n^{o} 13.303 / 2016$ \\
\hline $\begin{array}{l}\text { Art. } 54 \text {. Os contratos administrativos de que } \\
\text { trata esta Lei regulam-se pelas suas cláusulas } \\
\text { e pelos preceitos de direito público, aplicando-se- } \\
\text { lhes, supletivamente, os princípios da teoria geral } \\
\text { dos contratos e as disposiçôes de direito privado. }\end{array}$ & $\begin{array}{l}\text { Art. 68. Os contratos de que trata esta Lei } \\
\text { regulam-se pelas suas cláusulas, pelo disposto } \\
\text { nesta Lei e pelos preceitos de direito privado. }\end{array}$ \\
\hline $\begin{array}{l}\text { Art. 55. São cláusulas necessárias em todo } \\
\text { contrato as que estabeleçam:[...] } \\
\text { VII - os direitos e as responsabilidades das } \\
\text { partes, as penalidades cabiveis e os valores das } \\
\text { multas; } \\
\text { VIII - os casos de rescisão; } \\
\text { IX - o reconhecimento dos direitos da Admi- } \\
\text { nistração, em caso de rescisão administrativa } \\
\text { prevista no art. } 77 \text { desta Lei; [...] }\end{array}$ & $\begin{array}{l}\text { Art. 69. São cláusulas necessárias nos contratos } \\
\text { disciplinados por esta Lei:[...] } \\
\text { VI - os direitos e as responsabilidades das } \\
\text { partes, as tipificações das infrações e as respectivas } \\
\text { penalidades e valores das multas; } \\
\text { VII - os casos de rescisão do contrato e os } \\
\text { mecanismos para alteração de seus termos [...] }\end{array}$ \\
\hline $\begin{array}{l}\text { Art. 58. O regime jurídico dos contratos admi- } \\
\text { nistrativos instituído por esta Lei confere à } \\
\text { Administração, em relação a eles, a prerro- } \\
\text { gativa de: } \\
\text { I - modificá-los, unilateralmente [...] } \\
\text { II - rescindi-los, unilateralmente [...] } \\
\text { III - fiscalizar-lhes a execução [...] }\end{array}$ & \\
\hline $\begin{array}{l}\text { Art. } 65 . \text { Os contratos regidos por esta Lei poderão } \\
\text { ser alterados, com as devidas justificativas, nos } \\
\text { seguintes casos: } \\
\text { I - unilateralmente pela Administração: } \\
\text { II - por acordo das partes: } \\
{[\ldots . .]} \\
\$ 1^{\circ} \text { O contratado fica obrigado a aceitar, nas } \\
\text { mesmas condições contratuais, os acréscimos } \\
\text { ou supressões [...] }\end{array}$ & $\begin{array}{l}\text { Art. } 72 \text {. Os contratos regidos por esta Lei } \\
\text { somente poderão ser alterados por acordo entre } \\
\text { as partes [...] } \\
\text { Art. 81. Os contratos celebrados [...] contarão } \\
\text { com cláusula que estabeleça a possibilidade } \\
\text { de alteração, por acordo entre as partes, nos } \\
\text { seguintes casos: } \\
{[\ldots]} \\
\S 1^{\circ} \text { O contratado poderá aceitar, nas mesmas } \\
\text { condições contratuais, os acréscimos ou } \\
\text { supressões [...] }\end{array}$ \\
\hline $\begin{array}{l}\text { Art. 67. A execução do contrato deverá ser } \\
\text { acompanhada e fiscalizada por um represen- } \\
\text { tante da Administração especialmente desig- } \\
\text { nado, permitida a contratação de terceiros } \\
\text { para assisti-lo e subsidiá-lo de informações } \\
\text { pertinentes a essa atribuição. }\end{array}$ & \\
\hline
\end{tabular}




\begin{tabular}{|c|c|}
\hline Lei $n^{\circ}$ 8.666/1993 & Lei $n^{\circ} 13.303 / 2016$ \\
\hline $\begin{array}{l}\text { Art. 77. A inexecução total ou parcial do contrato } \\
\text { enseja a sua rescisão [...] } \\
\text { Art. 78. Constituem motivo para rescisão do } \\
\text { contrato: } \\
\text { Art. 79. A rescisão do contrato poderá ser: } \\
\text { I - [...] ato unilateral e escrito da Administração } \\
{[\ldots . .]} \\
\text { II - amigável, por acordo entre as partes [...] } \\
\text { III - judicial, nos termos da legislação [...] }\end{array}$ & \\
\hline $\begin{array}{l}\text { Art. 86. O atraso injustificado na execução } \\
\text { do contrato sujeitará o contratado à multa } \\
\text { de mora, na forma prevista no instrumento } \\
\text { convocatório ou no contrato. }[\ldots]\end{array}$ & $\begin{array}{l}\text { Art. 82. Os contratos devem conter cláusulas com } \\
\text { sanções administrativas a serem aplicadas em } \\
\text { decorrência de atraso injustificado na execução } \\
\text { do contrato, sujeitando o contratado a multa } \\
\text { de mora, na forma prevista no instrumento } \\
\text { convocatório ou no contrato. [...] }\end{array}$ \\
\hline $\begin{array}{l}\text { Art. 87. Pela inexecução total ou parcial do } \\
\text { contrato a Administração poderá, garantida } \\
\text { a prévia defesa, aplicar ao contratado as } \\
\text { seguintes sanções: } \\
\text { I - advertência; } \\
\text { II - multa }[\ldots] \\
\text { III - suspensão temporária }[. . .] \\
\text { IV - declaração de inidoneidade [...] } \\
\S 2^{\circ}[\ldots . . \text {, facultada a defesa prévia do interessado, } \\
\text { no respectivo processo, no prazo de } 5 \text { (cinco) } \\
\text { dias úteis. }\end{array}$ & $\begin{array}{l}\text { Art. 83. Pela inexecução total ou parcial do } \\
\text { contrato a empresa pública ou a sociedade de } \\
\text { economia mista poderá, garantida a prévia } \\
\text { defesa, aplicar ao contratado as seguintes } \\
\text { sanções: } \\
\text { I - advertência; } \\
\text { II - multa [...] } \\
\text { III - suspensão temporária [...] } \\
2^{\circ}[\text { [...] devendo a defesa prévia do interessado, } \\
\text { no respectivo processo, ser apresentada no } \\
\text { prazo de } 10 \text { (dez) dias úteis. }\end{array}$ \\
\hline $\begin{array}{l}\text { Art. 109. Dos atos da Administração decor- } \\
\text { rentes da aplicação desta Lei cabem: } \\
\text { I - recurso, no prazo de } 5 \text { ( } \text { cinco dias úteis }[\ldots] \\
\text { nos casos de: } \\
{[\ldots]} \\
\text { e) rescisão do contrato }[. . .] \\
\text { f) aplicação das penas de advertência, } \\
\text { suspensão temporária ou de multa }[\ldots]\end{array}$ & \\
\hline
\end{tabular}

Fonte: Elaboração própria.

Conforme destacado pela tabela comparativa, antes havia uma clara indicação de sujeição do regime de contratação aos preceitos de direito público e, somente de forma supletiva, os de direito privado. Com a Nova Lei das Estatais, o protagonismo desloca-se de forma expressa e indelével para o direito privado. 
No tocante à disposição das cláusulas necessárias, percebe-se uma ampliação naquelas que deverão tipificar infrações, casos de rescisão e mecanismos para alteração. Portanto, o contrato ganha maior relevo normativo nesse negócio jurídico, com destaque para a ausência de disposição normativa na Nova Lei das Estatais equivalente àqueles da Lei Geral de Licitações que prescrevem as prerrogativas da Administração para modificar e rescindir unilateralmente o contrato, bem como de fiscalizar-lhe a execução (cláusulas exorbitantes). Toda matéria normativa relacionada com casos de alteração contratual fica agora condicionada à dinâmica do regime de alteração consensual (consensualidade) ${ }^{46}$ Os acréscimos e supressões, por exemplo, não serão mais passíveis de imposição ao contratado, sob nenhuma hipótese. No caso da rescisão a situação é ainda mais relevante, porquanto sequer foram inseridas normas nesse sentido, ressalvadas as hipóteses estabelecidas no contrato.

Sobre o tema das sanções administrativas, ainda que o disposto no art. 82 da Lei das Estatais ostente disposição legal diversa daquela do art. 86 da Lei Geral de Licitações, ao que parece, as inovações na tessitura pouco afetam seu conteúdo.

Já o art. 83 traz modificações materiais e processuais mais sensíveis. Primeiramente, percebe-se que foi retirada a sanção de declaração de inidoneidade, restando somente as de advertência, multa e suspensão. Em segundo lugar, o prazo para apresentação de defesa prévia por parte do contratado dobrou, passando de cinco para 10 dias úteis. Por fim, também a despeito do processo administrativo de sancionamento, a Nova Lei das Estatais não previu a possibilidade de recurso, conforme consta no art. 109 da Lei Geral de Licitações. O direito a recurso administrativo, a princípio, não recebeu respaldo legal expresso, parecendo indicar que a defesa prévia seria o único momento administrativo em que a contratada poderia se defender da respectiva infração. Entretanto, a possibilidade de recurso parece buscar respaldo diretamente do disposto nos incisos LIV e LV do art. 5o da Constituição Federal, quando asseguram o direito ao devido processo legal, contraditório e ampla defesa, inclusive aos litigantes em processos administrativos. ${ }^{47}$

46 Para uma análise do fenômeno da consensualidade no direito administrativo e dos mecanismos de consenso na atividade administrativa, consultar: ALMEIDA, Fernando Dias Menezes de. Mecanismos de consenso no direito administrativo. In: ARAGÃO, Alexandre dos Santos; MARQUES NETO, Floriano de Azevedo (Coord.). Direito administrativo e seus novos paradigmas. Belo Horizonte: Fórum, 2008.

47 Ainda que não relacionadas com temática deste estudo, merecem destaque as seguintes modificações: a elevação da dispensa por valor, passando de $\mathrm{R} \$ 30.000,00$ e $\mathrm{R} \$ 16.000,00$ para $\mathrm{R}$ \$ 100.000,00 e R\$ 50.000,00, respectivamente; a inserção da possibilidade de contratação de projetos e estudos; 
Cumpre ressaltar, na linha do que já se defendeu anteriormente, que há base normativa para o direito a recurso na própria Lei n 9.784/1999, nos termos do inciso $X$ do parágrafo único do art. $2^{\circ}$ e também no art. 56, quando diz que "das decisões administrativas cabe recurso, em face de razões de legalidade e de mérito".

\section{A Lei das Estatais e a aplicação das sanções administrativas aos contratados}

Vencida a exposição das modificações da nova lei no âmbito das licitações e contratos de empresas públicas e sociedades de economia mista, passa-se à análise das normas concernentes ao processo administrativo de aplicação de sanções administrativas aos contratados das empresas estatais.

Atualmente, o processo de apuração de infrações e aplicação da respectiva sanção administrativa pode ser descrito em até cinco etapas. Constatado o inadimplemento contratual ou a mora, e depois de selecionada a correspondente penalidade em tese aplicável ao caso, o processo é instaurado com a emissão de um comunicado à contratada. Nessa correspondência consta o fato gerador, a penalidade a que está sujeito o contratado e, por fim, o prazo para a apresentação de defesa prévia, conforme $\S 2^{\circ}$ do art. 87 da Lei Geral de Licitações.

O segundo momento contempla a apresentação de defesa prévia pela contratada, que deverá observar o prazo para o exercício daquela, bem como expor as circunstâncias fáticas e as razões jurídicas capazes de afastar o sancionamento.

A terceira etapa consubstancia o momento de aplicação ou não da sanção, por decisão motivada, que será enviada à contratada por meio de ofício. Nela poderá constar a continuidade pela aplicação, seja pela ausência de defesa prévia ou pelo seu indeferimento. Também poderá constar a continuidade pela aplicação ajustada, no caso de deferimento parcial da defesa apresentada.

a alteração no sigilo do orçamento; a extensão da pena de impedimento relacionada com os proprietários das organizações punidas; a inclusão da matriz de riscos; a possibilidade de indicação de marcas; a restrição da desclassificação da proposta somente para caso insanável; a nova previsão de apenas uma fase recursal durante a licitação; e a criação de hipóteses em que o prazo de vigência máximo de cinco anos pode ser ampliado. No tocante aos contratos, cabe dizer que a nova legislação foi omissa no que tange às regras sobre fiscalização, recebimentos, pagamentos e rescisão. Nesse sentido, consultar: Joel de Menezes Niebuhr, Aspectos destacados do novo regime de licitações e contratações das estatais, op. cit. 
Como última situação possível, ter-se-ão o acatamento integral da defesa e o imediato arquivamento do processo. A Administração fará constar nessa comunicação análise sobre todos os pontos e provas levantados pela contratada, expondo ao final de cada um dos aspectos a respectiva decisão administrativa. Por fim, constará a possibilidade para interposição de recurso administrativo, com base no preceituado na alínea " $\mathrm{f}$ " do inciso I do art. 109 da Lei Geral de Licitações.

Ressalvado o caso em que a contratada logre êxito integral em seu pleito, tem-se no quarto momento o espaço para interposição de recurso administrativo. A contratada deverá, com base na resposta da Administração quanto à sua defesa prévia, trazer novos fatos, aspectos jurídicos e/ou evidências que possibilitem a revisão da sanção aplicada. Se a contratada não apresentar recurso, há a conclusão do processo, na esfera administrativa, pelo que a sanção aplicada não será mais modificável nesse âmbito, salvo situações excepcionais que imponham revisão de ofício pela Administração Pública.

Caso haja o recurso, caberá à Administração, por meio de instância superior àquela que instaurou o processo e se manifestou quanto à defesa prévia, apresentar seu parecer final sobre o caso, podendo rejeitar integralmente o pleito recursal, provê-lo parcial ou integralmente. A partir do teor da decisão, se for o caso, os ajustes sobre a sanção já aplicada serão realizados. Ressalta-se que a contratada pode apresentar recurso administrativo independentemente de ter se defendido previamente.

Com o advento da Nova Lei das Estatais, a maior discussão deverá gravitar em torno da existência ou não do direito a recurso na esfera administrativa, vez que as demais disposições processuais, com a exceção às inovações pontuais (v.g., o prazo para defesa prévia), permanecem no geral inalteradas.

Conforme asseverado, a Nova Lei das Estatais não prevê a possibilidade de reavaliação, pela própria Administração, de seus atos disciplinares, a partir da interposição de recurso administrativo pela contratada. Essa omissão se consubstancia no ponto mais polêmico em matéria de sanção administrativa na nova legislação. As contratadas administrativas não terão direito a recurso? As empresas públicas ou sociedades de economia mista não poderão admitir recurso em seus processos administrativos disciplinares?

A resposta parece enveredar numa só direção, ainda que por diferentes argumentos. Ainda que não exista nenhuma previsão expressa de aplicação supletiva da Lei Geral de Licitações para esse fim, parece possível defender até a aplicação analógica da alínea "f" do inciso I do art. 109 da Lei Geral de Licitações, vez que, em matéria penal, há expressa previsão de aplicação 
daquela legislação pelo art. 41 da Nova Lei das Estatais. Outra base normativa para o direito a recurso, inclusive mais sólida, decorre do inciso X do parágrafo único do art. $2^{\circ}$ e do art. 56 da Lei nº 9.784/1999, já anteriormente mencionados.

Por fim, cabe recuperar o que já foi dito, no sentido de que a ausência do direito a recurso representa clara e insofismável afronta aos princípios do devido processo legal, contraditório e ampla defesa, assegurados pelos incisos LIV e LV da Constituição Federal.

\section{Considerações finais}

O advento da Nova Lei das Estatais traz um novo marco para as empresas públicas, sociedades de economia mista e suas subsidiárias, com destacado impacto sobre seu regime de licitações e contratos. Como visto, a nova legislação retira do epicentro jurídico-normativo o direito público, repassando o protagonismo para o direito privado. Deixa a cena o regime legal fundado nas noções de supremacia do interesse público e cláusulas exorbitantes, para a estética da consensualidade ganhar os palcos da contratação das empresas estatais.

Com efeito, as inovações que derrogam o regime de cláusulas exorbitantes, em especial aquelas que possibilitam à Administração fiscalizar os contratos, alterá-los e rescindi-los unilateralmente, trazem um profundo impacto no regime de contratações das empresas públicas e sociedades de economia mista. Estas, exercendo atividades econômicas como singelos players de um mercado altamente competitivo, terão que se comportar, também no aspecto de suprimentos, como genuínas instituições privadas. Dito de outra maneira, elas deverão estabelecer contratos com seus fornecedores e prestadores de serviços em um cenário de quase total ausência de prevalência sobre a outra parte. Mas isso sem deixar as amarras e peculiaridades de uma submissão, ainda que mitigada, ao regime jurídico-administrativo, vez que integrantes da Administração Pública indireta e sujeitas aos princípios e regras constitucionais correspondentes.

Sobre a temática das sanções administrativas, há inovações tanto no aspecto material quanto processual. Naquele sentido, pode-se lembrar a exclusão da sanção de declaração de inidoneidade. Já na parte do processo administrativo, pode-se elencar o prazo em dobro para a defesa prévia da contratada, afora a inadequada e insubsistente omissão da previsão do 
direito a recurso da contratada, contra a decisão que lhe impõe a sanção administrativa.

Cumpre frisar que o direito a recurso tem respaldo constitucional, decorrente dos princípios do devido processo legal, contraditório e da ampla defesa, direito devidamente regulamentado pela Lei $n^{0}$ 9.784/1999, e o não recebimento ou conhecimento de recurso por ausência de previsão legal consubstanciaria decisão administrativa eivada de vício de manifesta ilegalidade e inconstitucionalidade, a ensejar a nulidade da respectiva penalidade aplicada e reclamar a revisão judicial.

Inclusive, a leitura dos incisos LIV e LV do art. $5^{\circ}$ da Constituição Federal conjugada com o inciso $X$ do parágrafo único do art. $2^{\underline{0}}$ e art. 56 da Lei no 9.784/1999 viabilizam a regulamentação da fase recursal pelas respectivas empresas estatais, no seu respectivo âmbito de atuação.

Em síntese, ainda que se reconheçam pontos positivos nas inovações trazidas pela Nova Lei das Estatais, em especial na parte do novo regime de contratações das empresas estatais, diversos temas reclamam maiores debates e reflexões, com o amadurecimento dos agentes que atuam internamente nessas entidades, bem como daqueles que figuram como seus fornecedores em geral. Se o saldo será positivo em maior ou menor escala, essa resposta somente o tempo poderá trazer!

\section{Referências}

ALMEIDA, Fernando Dias Menezes de. Mecanismos de consenso no direito administrativo. In: ARAGÃO, Alexandre dos Santos; MARQUES NETO, Floriano de Azevedo (Coord.). Direito administrativo e seus novos paradigmas. Belo Horizonte: Fórum, 2008. p. 335-349.

ALTOUNIAN, Cláudio Sarian. Obras públicas: licitação, contratação, fiscalização e utilização. 2. ed. Belo Horizonte: Fórum, 2009.

AMARAL, Antônio Carlos Cintra do. Licitação e contrato administrativo: estudos, pareceres e comentários. 2. ed. Belo Horizonte: Fórum, 2009.

BRASIL. Constituição (1988). Constituição da República Federativa do Brasil: promulgada em 5 de outubro de 1988. Brasília, DF, 5 out. 1988. Disponível em: $<$ http://www.planalto.gov.br/ccivil_03/constituicao/constituicaocompilado. htm>. Acesso em: 14 out. 2016. 
. Lei $n^{\underline{0}}$ 8.666, de 21 de junho de 1993. Regulamenta o art. 37, inciso XXI, da Constituição Federal, institui normas para licitações e contratos da Administração Pública e dá outras providências. Disponível em: $<$ www.planalto. gov.br/ccivil_03/LEIS/L8666cons.htm>. Acesso em: 14 out. 2016.

. Lei $n^{\circ}$ 9.784, de 29 de janeiro de 1999. Regulamenta o processo administrativo no âmbito da Administração Pública Federal. Disponível em: <www.planalto. gov.br/ccivil_03/leis/L9784.htm>. Acesso em: 14 out. 2016.

. Lei $n^{\mathrm{o}}$ 10.520, de 17 de julho de 2002. Institui, no âmbito da União, Estados, Distrito Federal e Municípios, nos termos do art. 37, inciso XXI, da Constituição Federal, modalidade de licitação denominada pregão, para aquisição de bens e serviços comuns, e dá outras providências. Disponível em: <www.planalto. gov.br/ccivil_03/leis/2002/L10520.htm>. Acesso em: 14 out. 2016.

. Lei $n^{\mathrm{o}}$ 13.303, de 30 de junho de 2016. Dispõe sobre o estatuto jurídico da empresa pública, da sociedade de economia mista e de suas subsidiárias, no âmbito da União, dos Estados, do Distrito Federal e dos Municípios. Disponível em: <www.planalto.gov.br/ccivil_03/_Ato2015-2018/2016/Lei/ L13303.htm>. Acesso em: 14 out. 2016.

CAETANO, Marcello. Manual de direito administrativo. v. I, Coimbra: Livraria Almedina, 1991.

CARVALHO FILHO, José dos Santos. Manual de direito administrativo. 31. ed. São Paulo: Atlas, 2017.

CRISTÓVAM, José Sérgio da Silva. Administração pública democrática e supremacia do interesse público: novo regime jurídico-administrativo e seus princípios constitucionais estruturantes. Curitiba: Juruá, 2015.

. Princípios constitucionais: razoabilidade, proporcionalidade e argumentação jurídica. 2. ed. Curitiba: Juruá, 2016.

DIAS, Eduardo Rocha. Sanções administrativas aplicáveis a licitantes e contratados. São Paulo: Dialética, 1997.

DI PIETRO, Maria Sylvia Zanella. Direito administrativo. 30. ed. Rio de Janeiro: Forense, 2017.

FERNANDES, Jorge Ulisses Jacoby. Tribunais de Contas do Brasil: jurisdição e competência. 2. ed. Belo Horizonte: Fórum, 2008.

FREITAS, Walter. Gestão de contratos: melhores práticas voltadas aos contratos empresariais. São Paulo: Atlas, 2009. 
GUIMARÃES, Edgar; SANTOS, José Anacleto Abduch. Lei das estatais: comentários ao regime jurídico licitatório e contratual da Lei 13.303-16. Belo Horizonte: Fórum, 2017.

JUSTEN FILHO, Marçal. Comentários à lei de licitações e contratos administrativos. 9. ed. São Paulo: Dialética, 2002.

. Curso de direito administrativo. 12. ed. São Paulo: Revista dos Tribunais, 2016.

. Estatuto jurídico das empresas estatais: Lei 13.303/16 "Lei das Estatais". São Paulo: Revista dos Tribunais, 2016.

MATTOS, Mauro Roberto Gomes de. O contrato administrativo. Rio de Janeiro: América Jurídica, 2001.

MEIRELLES, Hely Lopes. Direito administrativo brasileiro. 13. ed. São Paulo: Revista dos Tribunais, 1987.

MELLO, Celso Antônio Bandeira de. Curso de direito administrativo. 32. ed. São Paulo: Malheiros, 2015.

MOREIRA NETO, Diogo de Figueiredo. O futuro das cláusulas exorbitantes nos contratos administrativos. In: ARAGÃO, Alexandre dos Santos; MARQUES NETO, Floriano de Azevedo (Coord.). Direito administrativo e seus novos paradigmas. Belo Horizonte: Fórum, 2008. p. 571-592.

NIEBUHR, Joel de Menezes. Aspectos destacados do novo regime de licitações e contratações das estatais. 2016. Disponível em: <www.mnadvocacia.com.br/ publicacoes/novo-regime-de-licitacoes-e-contratacoes-das-estatais/>. Acesso em: 10 nov. 2016.

2015.

. Licitação pública e contrato administrativo. 4. ed. Belo Horizonte: Fórum,

NOHARA, Irene Patrícia. Mudanças promovidas pela nova Lei das Estatais: pontos fortes e fracos. Disponível em: <www.direitoadm.com.br>. Acesso em: 4 jun. 2017.

OLIVEIRA, Yara Beatriz Cruz de. Dosimetria da penalização nos contratos administrativos: dinâmica para a formulação do juízo de proporcionalidade. Porto Alegre: Ingep, 2013.

OSÓRIO, Fábio Medina. Direito administrativo sancionador. 2. ed. São Paulo: Revista dos Tribunais, 2005. 
PÉRCIO, Gabriela Verona. Contratos administrativos. Curitiba: Negócios Públicos do Brasil, 2008.

PIMENTEL, Cleusa. Roteiro do gestor de contratos públicos. São Paulo: Vianna Treinamento e Assessoria, 2010. CD-ROM.

ROCHA, Wagner. Gestão pública - Módulo V - 14. Gestão de contratos administrativos. 2013. Disponível em: <http://gestaopublicaeficiente.blogspot. com.br/2013/06/gestao-publica-modulo-v-14-gestao-de.html>. Acesso em: 14 out. 2016.

SUPERIOR TRIBUNAL DE JUSTIÇA. Manual do gestor de contratos. 2005. Disponível em: <http://bdjur.stj.gov.br/dspace/handle/2011/2175>. Acesso em: 14 out. 2016.

TRIBUNAL DE CONTAS DO ESTADO DO TOCANTINS. Manual de gestão de contratos. 2007. Disponível em: <www.tce.to.gov.br/sitephp/aplic/ controleInterno/docs/Manual_Gestao_Contrato.pdf>. Acesso em: 14 out. 2016.

UNIVERSIDADE FEDERAL DE VIÇOSA. Manual de gestão de contratos. 2008. Disponível em: <ftp://ftp.ufv.br/Proplan2/Formularios/ manualGestaoContratos.pdf>. Acesso em: 14 out. 2016.

VIEIRA, Antonieta Pereira et al. Gestão de contratos de terceirização na administração pública. 3. ed. Belo Horizonte: Fórum, 2008. 